\title{
Aplicação de nitrogênio no crescimento inicial de framboeseira no sul do Brasil
}

\section{Sulian Junkes Dal Molin \\ Pâmella Soldatelli \\ Djalma Eugênio Schmitt}

Universidade do Estado de Santa Catarina. Departamento de Solos e Recursos Naturais, área de Química e Fertilidade do Solo.

$$
\begin{aligned}
& \begin{array}{l}
\text { E-mails: dalmolin.sj@gmail.com } \\
\text { pam soldatelli@hotmail.com }
\end{array} \\
& \text { djalma.schmitt@gmail.com }
\end{aligned}
$$

\section{Gabriel Fernandes Pauletti Universidade de Caxias do Sul. Campus-Sede: Rua Francisco Getúlio Vargas, 1130 CEP 95070-560 - Caxias do Sul. RS.

Recebido em: 12 janeiro 2018. Aceito em: 04 fevereiro 2018.

DOI: http://dx.doi.org/10.21674/2448-0479.43.421-431

\section{Resumo}

A exigência nutricional na cultura da framboeseira difere entre a fase de estabelecimento e a fase produtiva, principalmente para as cultivares não reflorescentes que apenas apresentam crescimento vegetativo no primeiro ano. O objetivo deste trabalho foi avaliar a resposta à aplicação de nitrogênio na framboeseira Tulameen quanto ao desenvolvimento inicial das plantas. O experimento foi realizado no ano de 2012 na área experimental do Campus da Universidade de Caxias do Sul localizado em Vacaria, RS, sobre um Latossolo Bruno. Os tratamentos consistiram da aplicação de seis doses de $\mathrm{N}\left(0,40,80,120,160\right.$ e $\left.200 \mathrm{~kg} \mathrm{ha}^{-1}\right)$, aplicados em dez parcelas ao longo do ciclo da cultura. Utilizou-se o delineamento de blocos ao acaso, com quatro repetições. Foram avaliadas as variáveis: índice de área foliar (IAF), número e diâmetro médio de hastes e a concentração de nutrientes em tecido foliar. A adubação nitrogenada não influenciou o número e nem o diâmetro médio das hastes, mas aumentou o IAF da cultura. As concentrações de nutrientes em tecido foliar da framboeseira não foram influenciadas pela aplicação de nitrogênio, exceto para os teores de cálcio e cobre.

Palavras-chave: Rubus idaeus. Adubação nitrogenada. índice de área foliar.

\section{Abstract}

\section{Nitrogen application on initial growth of red raspberry in south of Brazil}

Nutrient requirement in the red raspberry differs between the establishment and the reproductive phase, especially for floricane cultivars that only grow vegetative in the first year. This study aimed to evaluate the nitrogen application in the Tulameen red raspberry on the initial plant growth. The experiment was carried out in 2012/2013 
Sulian J. Dal Molin et al. Aplicação de nitrogênio no crescimento inicial de framboeseira no Sul do Brasil

in the experimental area of the University of Caxias do Sul on an Oxisol in Vacaria, RS. The treatments consisted of the six $\mathrm{N}$ rates application $\left(0,40,80,120,160\right.$ and $\left.200 \mathrm{~kg} \mathrm{ha}^{-1}\right)$, split in 10 application throughout the crop cycle. A randomized block design with four replications was used. The following variables were evaluated: leaf area index (LAl), number and mean diameter of the primocanes and nutrient concentration in leaf tissue. Nitrogen fertilization not affects the number and the mean diameter of the primocanes, but increased the crop LAI. The nutrient concentrations in leaf tissue of the red raspberry were not influenced by the nitrogen application, except for the calcium and copper contents.

Keywords: Rubus idaeus. Nitrogen fertilization. Leaf area index.

\section{Introdução}

O nitrogênio $(\mathrm{N})$ é o principal nutriente requerido pelas plantas e pode ser absorvido do solo ou através da fixação de $\mathrm{N}$ atmosférico por bactérias em algumas espécies de plantas. Cerca de $95 \%$ do $\mathrm{N}$ presente no solo está na forma orgânica, fazendo com que a taxa de mineralização da matéria orgânica (MO) presente no solo regule a disponibilidade de $\mathrm{N}$ para as plantas (CAMARGO et al., 1997). Quando a taxa de mineralização é insuficiente para o adequado crescimento das plantas, é necessária a complementação de $\mathrm{N}$ através de fertilizantes ao solo (COMISSÃO DE QUÍMICA E FERTILIDADE DO SOLO RS/SC, 2016).

Na região Sul do Brasil, para as espécies frutíferas é recomendado a aplicação de $\mathrm{N}$ de acordo com o teor de MO do solo e a expectativa de rendimento para a cultura (CQFSRS/SC, 2016). No entanto, para a cultura da framboeseira, não há recomendação oficial de adubação e calagem para esta região. Em países mais tradicionais na produção de pequenas frutas, a framboeseira e a amoreira-preta são agrupadas quanto a valores de referência no critério de adubação e diagnóstico do estado nutricional das plantas devido à similaridade das espécies (STRIK, 2013; BUSHWAY et al., 2008). Para os estados do Rio Grande do Sul e Santa Catarina há recomendação dos valores de referência apenas para a amoreira preta (COMISSÃO DE QUÍMICA E FERTILIDADE DO SOLO RS/SC, 2016), que tem sido utilizado para definir as recomendações para a framboesa.

O fornecimento abaixo do adequado de $\mathrm{N}$ para a framboeseira está associada ao menor rendimento (BUSHWAY et. al., 2008), e também à qualidade dos frutos. Na deficiência deste nutriente as folhas apresentamse cloróticas, as hastes com baixo vigor, e as pontas das folhas mais velhas podem ficar avermelhadas. Por outro lado, as plantas com mais de $3 \%$ de $\mathrm{N}$ podem ser muito vigorosas e, como resultado, menor produção de botões florais e hastes mais fracas (BUSHWAY et. al., 2008).

Parte da necessidade de $\mathrm{N}$ para a cultura da framboeseira pode ser estimada pela quantidade exportada nos frutos. A concentração média de $\mathrm{N}$ no fruto é de 1,6 kg por tonelada colhida (STRIK et al., 2013), o que representaria a necessidade de $16 \mathrm{~kg}_{\text {de N ha-1 }} \mathrm{ano}^{-1}$ para uma produção de 10 toneladas. Porém este valor não representa a necessidade de $\mathrm{N}$ para o desenvolvimento vegetativo e nem as possíveis formas de perdas $\mathrm{N}$.

As recomendações de $\mathrm{N}$ para framboeseira variam em função da região de produção, da cultivar e da fase da cultura. As doses recomendadas para diferentes situações podem variar de 27 a $110 \mathrm{~kg} \mathrm{de} \mathrm{N} \mathrm{ha-1}^{-1}$ ano-1 $^{-1}$ (STRIK; BRYLA, 2015). A exigência de $\mathrm{N}$ no ano de implantação da framboeseira é diferente, normalmente 
Sulian J. Dal Molin et al. Aplicação de nitrogênio no crescimento inicial de framboeseira no Sul do Brasil

menor, em comparação aos anos subsequentes (STRIK; BRYLA, 2015; BURNEY et al., 2007; HART et. al., 2006). Para cultivares não reflorescentes, aquelas que frutificam apenas nas hastes velhas, as diferenças de exigências nutricionais entre o ano de implantação e os anos subsequentes são ainda maiores, pois apenas ocorre crescimento vegetativo no ano de implantação, como a Tulameen, que diferem das cultivares tradicionalmente utilizadas no Brasil. O objetivo deste trabalho foi avaliar a resposta do desenvolvimento inicial da framboeseira Tulameen à aplicação de nitrogênio no Sul do Brasil.

\section{Materiais e Métodos}

O experimento foi conduzido no ano agrícola de 2012/2013 na área experimental da Universidade de

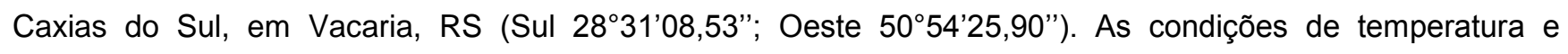
precipitação durante a condução dos estudos são apresentadas na Figura 1. O estudo foi implantado sobre um Latossolo Bruno em área de pastagem natural. As condições químicas antes e após a correção da acidez do solo e da fertilidade são apresentadas na Tabela 1 . Antes do plantio foi aplicado $16 \mathrm{Mg} \mathrm{ha}^{-1}$ de calcário dolomítico (PRNT 100\%), $135 \mathrm{~kg} \mathrm{ha}^{-1}$ de $\mathrm{P}_{2} \mathrm{O}_{5}$ na forma de super fosfato triplo e $60 \mathrm{~kg} \mathrm{ha}^{-1} \mathrm{de} \mathrm{K}_{2} \mathrm{O}$ na forma de cloreto de potássio conforme recomendação para a cultura da amora-preta (COMISSÃO DE QUÍMICA E FERTILIDADE DO SOLO RS/SC, 2004).

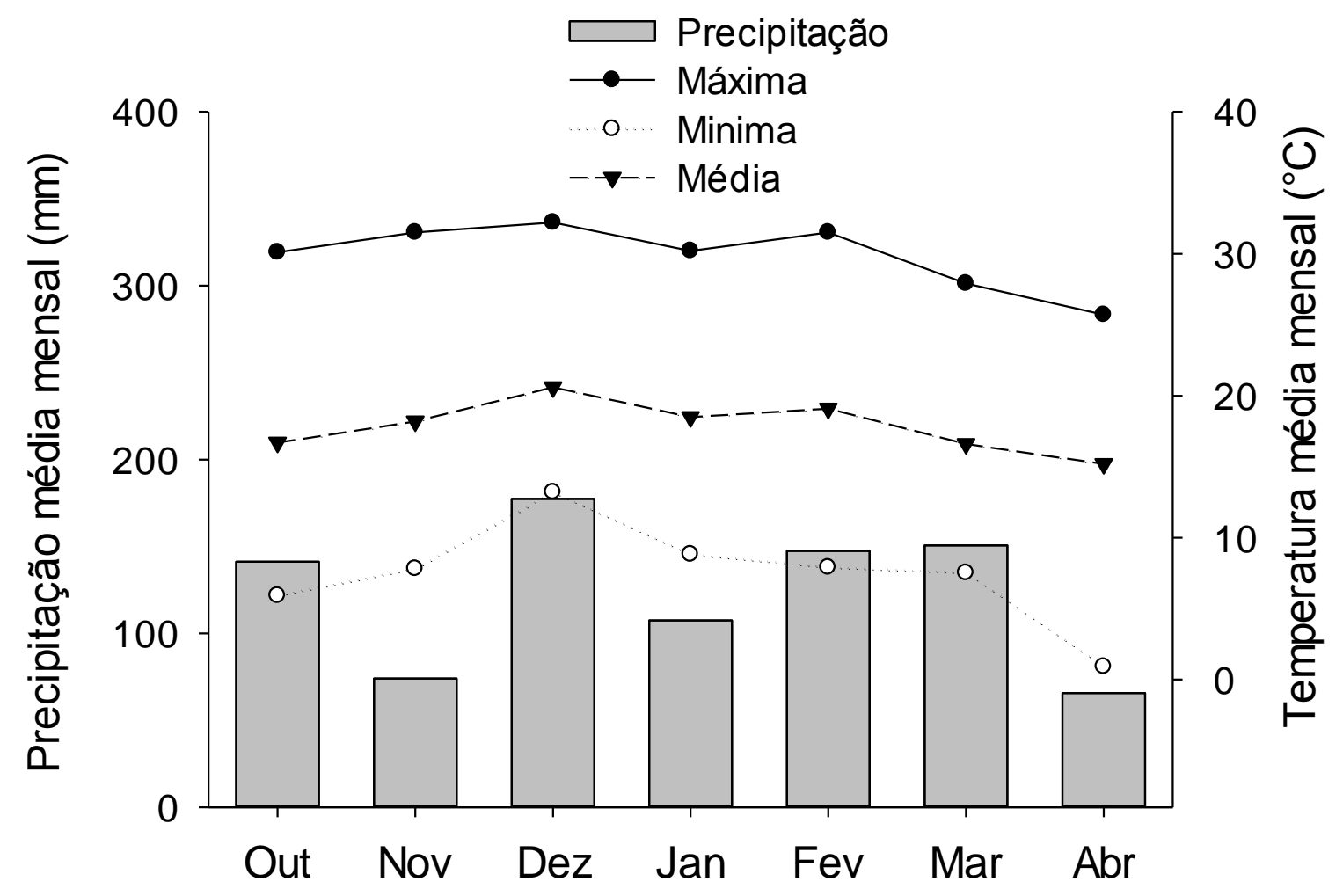

Figura 1. Temperatura e precipitação pluviométrica média mensal na área experimental ocorrida de outubro de 2012 a abril de 2013. (Fonte: Estação meteorológica da Embrapa Uva e Vinho de Vacaria, RS.) 
Sulian J. Dal Molin et al. Aplicação de nitrogênio no crescimento inicial de framboeseira no Sul do Brasil

Antes da implantação do experimento foi realizado o preparo do solo e a instalação do sistema de irrigação e tutoramento. O preparo do solo consistiu em realizar a subsolagem da área, incorporação de corretivos e levantamento de camalhões com altura de $0,40 \mathrm{~m}, 1,0 \mathrm{~m}$ de base e 0,60 $\mathrm{m}$ de superfície. Foi utilizado o sistema de irrigação por gotejamento com espaçamento entre emissores de $0,30 \mathrm{~m}$ e vazão de $2 \mathrm{~L}$ hora-1 por emissor. $\mathrm{O}$ sistema de condução adotado foi o sistema em $\mathrm{V}$, que consiste em conduzir as hastes em arames paralelos a aproximadamente 1,0 e 1,7 m de altura do solo. As mudas de framboeseira da cultivar Tulameen foram plantadas na primeira semana de outubro de 2012 com espaçamentos de 0,30 m entre plantas e $3 \mathrm{~m}$ entre filas.

Tabela 1. Caracterização química do solo antes e após a calagem e adubação.

\begin{tabular}{|c|c|c|c|c|c|c|c|c|c|}
\hline \multirow{2}{*}{ Coleta } & Argila & $\mathrm{MO}$ & $s$ & & $\mathrm{P}^{*}$ & $\mathrm{Cu}$ & $\mathrm{Zn}$ & $\mathrm{B}$ & $\mathrm{Mn}$ \\
\hline & \multicolumn{3}{|c|}{---- \% ---- } & \multicolumn{6}{|c|}{ - } \\
\hline Antes & 47 & 5,3 & 4,8 & 2 & 88 & 12,9 & 3,3 & 0,1 & 32 \\
\hline \multirow[t]{3}{*}{ Após } & 43 & 5,6 & 33 & 3 & 110 & 5 & 2,3 & 0,3 & 2 \\
\hline & $\mathrm{pH}_{\text {água }}$ & $\mathrm{Ca}$ & $\mathrm{Mg}$ & $\overline{\mathrm{Al}}$ & $\mathrm{H}+\mathrm{Al}$ & CTC $^{1}$ & $\mathrm{CTC}_{\mathrm{pH} 7}$ & \multicolumn{2}{|c|}{ Saturação \% } \\
\hline & & & \multicolumn{5}{|c|}{-------------- $\mathrm{cmol}_{\mathrm{c}} \mathrm{dm}^{-3}$-------------- } & $\mathrm{Al}$ & Bases \\
\hline Antes & 4,6 & 1,2 & 0,7 & 7 & 21,8 & 8,7 & 23,9 & 76 & 8,9 \\
\hline Após & 6,6 & 8,7 & 7,5 & 0 & 2 & 16,5 & 18,5 & 0 & 89,1 \\
\hline
\end{tabular}

* Extraídos por Mehlich-1; ${ }^{1}$ Efetiva.

Os tratamentos consistiram em seis doses de $\mathrm{N}$ arranjados em delineamento experimental de blocos casualizados com quatro repetições. As doses utilizadas foram: 0, 40, 80, 120, 160 e $200 \mathrm{~kg} \mathrm{ha}^{-1}$ de N na forma de ureia ( $45 \%$ de N). A aplicação da ureia foi parcelada em 10 vezes espaçadas a cada 15 dias com início 15 dias após o plantio. Em cada aplicação, a ureia foi diluída em 3,6 L de água com a finalidade de simular a aplicação de $\mathrm{N}$ via fertirrigação.

Foram avaliados o índice de área foliar (IAF), o número e o diâmetro médio de hastes emergidas do solo e a concentração de nutrientes no tecido foliar. O IAF foi mensurado em abril de 2013, após a paralização do crescimento vegetativo, com o aparelho AccuPAR modelo LP-80. A concentração de N, fósforo $(P)$, potássio $(K)$, cálcio $(\mathrm{Ca})$, magnésio $(\mathrm{Mg})$, enxofre $(\mathrm{S})$, cobre $(\mathrm{Cu})$, zinco $(\mathrm{Zn})$, manganês $(\mathrm{Mn})$ e boro $(\mathrm{B})$ em tecido foliar foi realizada em amostra contendo 20 trifólios coletados no terço médio das hastes e determinados conforme metodologia proposta por Tedesco et al. (1995). O diâmetro de hastes emergidas do solo foi mensurado com auxílio de um paquímetro ao nível do solo. As variáveis de produção não foram avaliadas neste trabalho, devido a cultivar utilizada ser de habito não reflorescente, ou seja, com produção apenas em hastes velhas ou de ano. Os dados foram submetidos à análise de variância (anova) e quando verificada significância, os dados foram ajustados a modelos de regressão ( $P \leq 0,05$ e $P \leq 0,01)$. 


\section{Resultados e Discussões}

A aplicação de nitrogênio $(N)$ aumentou o índice de área foliar (IAF) da framboeseira. $O$ incremento do IAF foi linear com o aumento da dose de $\mathrm{N}$ aplicada ao solo até 1,53 na maior dose (Figura 2). O IAF é a relação entre a área foliar e uma determinada área de solo, assim, quanto maior o IAF maior será o crescimento vegetativo. $\mathrm{O}$ aumento da disponibilidade de $\mathrm{N}$ para as plantas proporciona incremento linear no IAF das mesmas (COWLING; FIELD, 2003). Neste caso, o aumento no IAF foi devido ao maior número de folhas promovido pelo maior crescimento de parte aérea que ocorre com o incremento da disponibilidade de N (PEREIRA et. al., 2013).

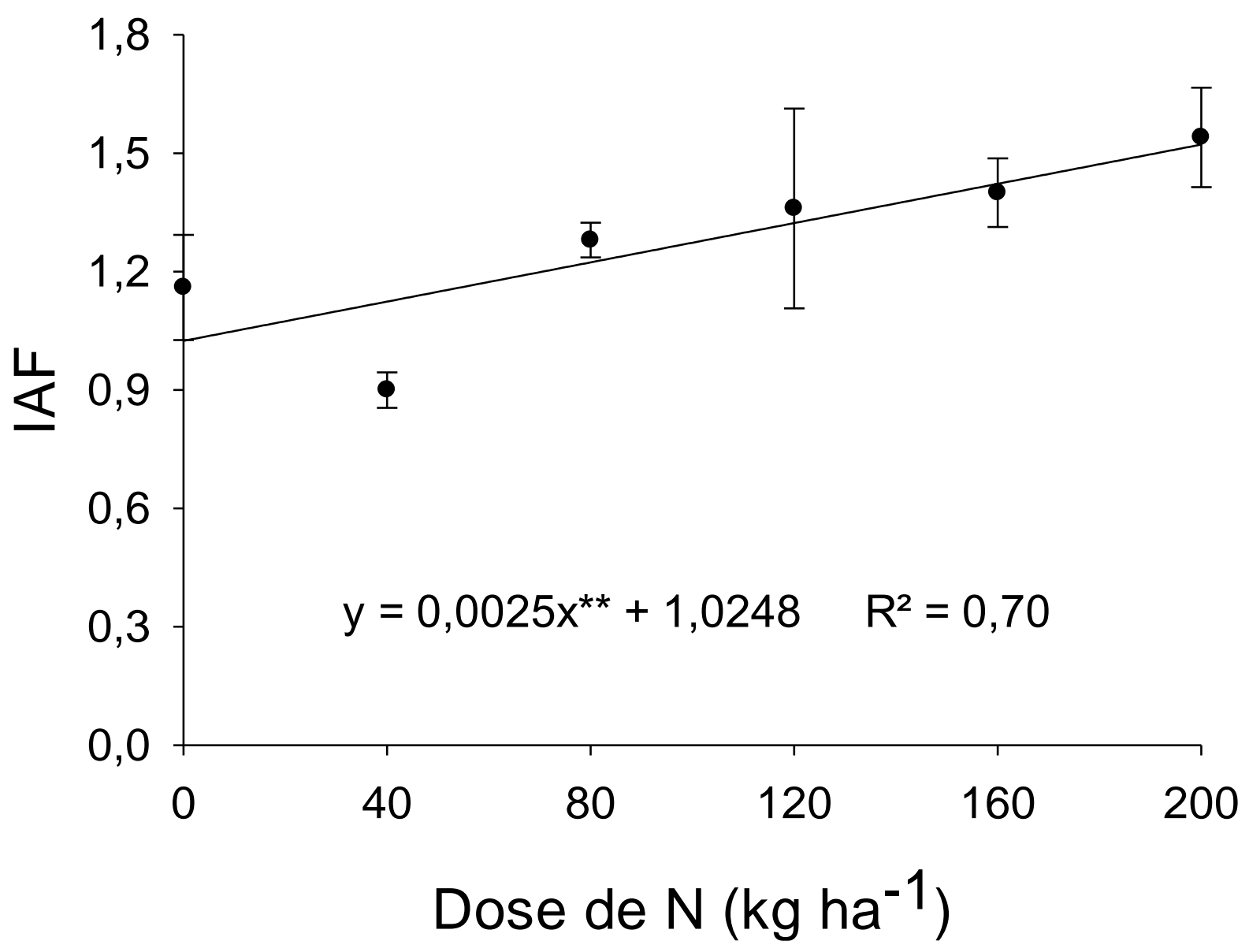

Figura 2. Índice de área foliar (IAF) da framboeseira em função de doses de $N$. **Significativo a $P \leq 0,01$. As barras representam o erro padrão para cada tratamento.

A aplicação de $\mathrm{N}$ não interferiu no número de hastes emergidas do solo e nem no diâmetro médio das mesmas (Tabela 2). O número médio de hastes emergidas do solo foi de 34,4. Em experimentos com amoreirapreta também não houve incremento no número de hastes em função do aumento nas doses de N (PEREIRA et. al., 2013), mostrando que a quantidade de hastes que emergem do solo pode não ter relação direta com a disponibilidade de $\mathrm{N}$, mas sim com outros fatores como a densidade de plantio (CURI et. al., 2015) e as 
Sulian J. Dal Molin et al. Aplicação de nitrogênio no crescimento inicial de framboeseira no Sul do Brasil

características da planta, como volume de produção de raízes e a indução de gemas de brotação nas mesmas. De maneira similar ao número de hastes, o diâmetro médio das hastes emergidas ao nível do solo também não foi afetado pela aplicação de $\mathrm{N}$, apresentando média de $8,0 \mathrm{~mm}$.

Tabela 2. Número e diâmetro de hastes em função da dose de $\mathrm{N}$ aplicada.

\begin{tabular}{lcc}
\hline Dose de N $\left(\mathrm{kg} \mathrm{ha}^{-1}\right)$ & Número & Diâmetro médio $(\mathrm{mm})$ \\
\cline { 2 - 3 } 40 & 30,0 & 7,7 \\
80 & 31,0 & 7,7 \\
120 & 42,0 & 8,2 \\
160 & 32,7 & 8,2 \\
200 & 34,7 & 8,2 \\
\hline Média & 36,2 & 8,2 \\
P & 34,4 & 8,0 \\
CV\% & $0,2819^{\text {ns }}$ & $0,3621^{\text {ns }}$ \\
\hline
\end{tabular}

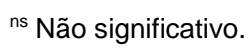

Os teores altos de matéria orgânica (MO) no solo onde as plantas foram cultivadas (Tabela 1) podem contribuir no fornecimento de $\mathrm{N}$ as plantas (CAMARGO et al., 1997). A mineralização da MO, beneficiada pela calagem e revolvimento do solo, pode ter fornecido quantidades suficientes de $\mathrm{N}$ mineral as plantas para que não houvesse incremento no número e no diâmetro médio de hastes emergidas do solo (Tabela 2). Além disso, as recomendações de aplicação de $\mathrm{N}$ para as espécies frutíferas no ano de implantação é menor em comparação à adubação de manutenção (COMISSÃO DE QUÍMICA E FERTILIDADE DO SOLO RS/SC, 2016), inclusive para a framboeseira (BURNEY et al., 2007; HART et. al., 2006). Por outro lado, a resposta linear no IAF com o incremento da dose de $\mathrm{N}$ e, embora não alcançado significância estatísticas, os maiores valores de número e diâmetro de hastes nas doses a partir de $80 \mathrm{~kg} \mathrm{ha}^{-1}$ de $\mathrm{N}$, evidenciam a necessidade de complementação de $\mathrm{N}$ para as plantas, principalmente em solos de baixa MO.

Os teores de macronutrientes em tecido foliar não foram influenciados pela aplicação de $\mathrm{N}$, exceto para os teores de cálcio $(\mathrm{Ca})$ (Tabela 3). As concentrações de fósforo $(\mathrm{P})$, potássio $(\mathrm{K})$, magnésio $(\mathrm{Mg})$ e enxofre $(\mathrm{S})$, com teores médios de 0,23, 1,31, 0,48 e 0,20\% respectivamente, estão dentro da faixa considerada suficiente para Strik (2013), porém são considerados abaixo do valor suficiente para Bushway et al. (2008). Já a concentração de N, com teor médio de 3,27\%, ficou acima da faixa considerada suficiente, não sendo afetado pela aplicação de $\mathrm{N}$ no solo. Embora não tenha apresentado diferença entre os tratamentos, a dose zero de $\mathrm{N}$ que proporcionou o menor teor de $\mathrm{N}$ nas folhas, está dentro da faixa adequada de 2,3 a 3,0\% para Strik (2013) 2,0 a 3,0 \% para Bushway et al. (2008). No entanto, os teores foliares de $\mathrm{N}$ podem mudar em função do ano de 
Sulian J. Dal Molin et al. Aplicação de nitrogênio no crescimento inicial de framboeseira no Sul do Brasil

avaliação e de outras condições químicas do solo que não somente a disponibilidade de N, como pH e saturação por bases (SIKIRIC et al., 2015; SIKIRIC et al., 2011).

Os teores de Ca nas folhas aumentaram com a aplicação de $\mathrm{N}$ ao solo. $\mathrm{O}$ incremento teve comportamento quadrático com concentração máxima de $1,80 \%$ na dose ajustada de $180 \mathrm{~kg}$ de N ha-1 (Figura 3). $O$ aumento nas concentrações de Ca no tecido foliar pode ser devido ao fato do Ca ser absorvido, predominantemente, por fluxo de massa (RUIZ et al., 1999), o qual foi influenciado pelo incremento de área foliar (Figura 3) que aumenta o fluxo de água entre o solo a planta e a atmosfera.

As concentrações de micronutrientes, a exceção do cobre $(\mathrm{Cu})$, também não foram influenciadas pela aplicação de $\mathrm{N}$ ao solo (Tabela 3). Os teores médios de zinco (Zn) e boro (B), 26,1 e 36,7 mg kg-1 respectivamente, se encontram dentro da faixa considerada suficiente (STRIK, 2013; BUSHWAY et al., 2008). A concentração média de manganês (Mn) no tecido foliar foi de $380,0 \mathrm{mg} \mathrm{kg}^{-1}$, sendo considerado excessivo para a cultura da framboeseira (STRIK, 2013; BUSHWAY et al., 2008). Altos teores foliares de Mn também são observados em outros trabalhos (DRESLER et al., 2015), possivelmente em função da alta disponibilidade deste nutriente no solo, principalmente em condições de $\mathrm{pH}$ mais baixo e nas camadas mais profundas onde não há efeito da calagem. Apesar dos altos teores foliares de $\mathrm{Mn}$, não foi observado sintomas de toxidez nas plantas, o que pode ser devido a maior tolerância da cultivar a altos teores, mostrando a necessidade de se realizar estudos de calibração para os teores foliares em nível regional. 
Tabela 3. Teores de macro e micronutrientes em tecido foliar em função da dose de $\mathrm{N}$ aplicada.

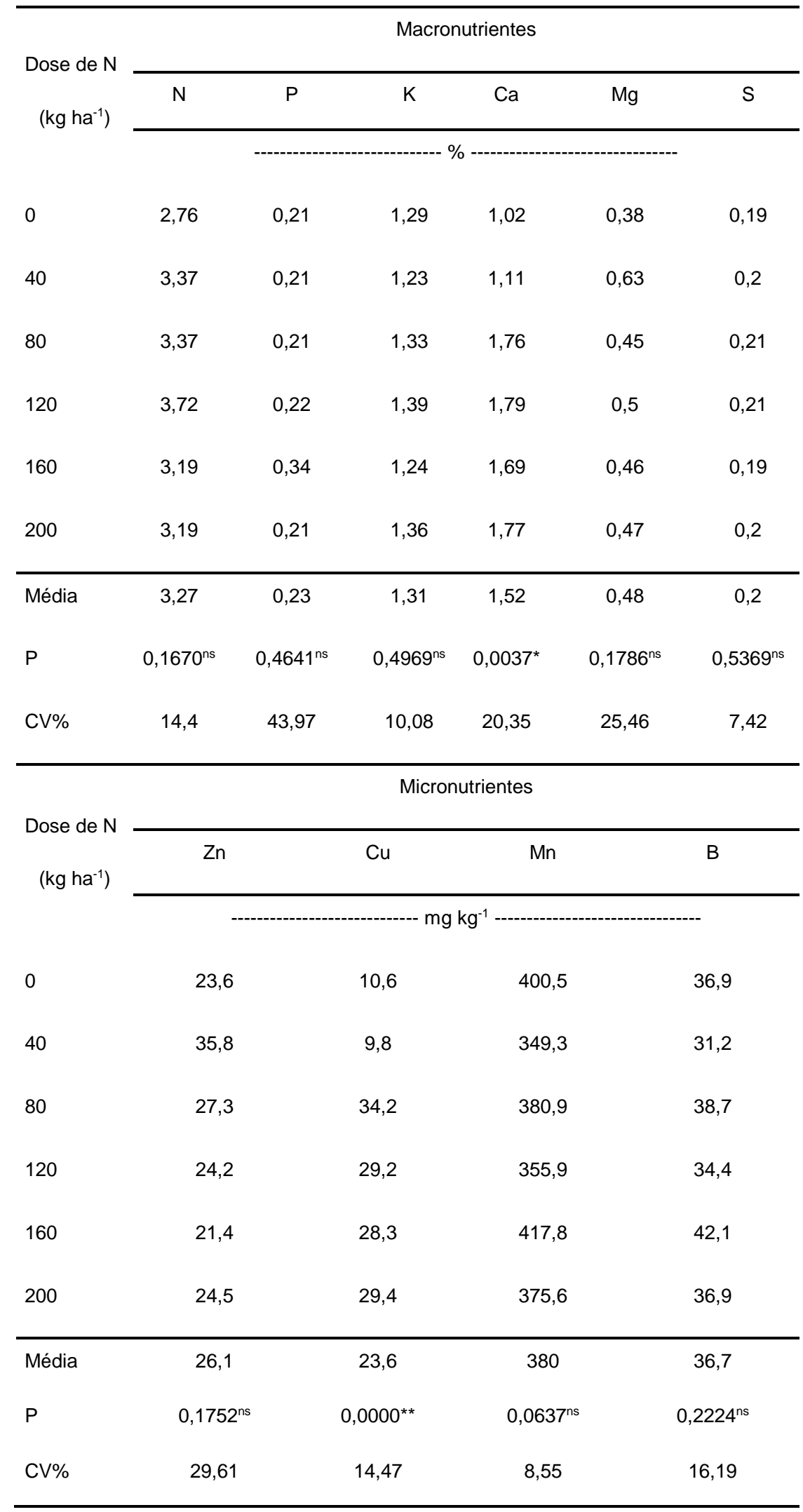

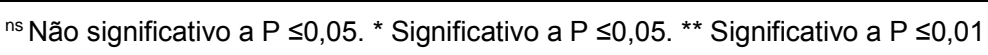


As concentrações de $\mathrm{Cu}$ no tecido foliar apresentaram resposta quadrática às doses de $\mathrm{N}$ aplicada (Figura 3), sendo a dose estimada de $149 \mathrm{~kg}$ de $\mathrm{N} \mathrm{ha}^{-1}$ que proporcionou a maior concentração de Cu no tecido foliar, 33,6 mg kg-1. O teor médio de Cu no tecido foliar foi de 23,6 mg kg-1 (Tabela 3) ficando dentro da faixa considerada suficiente para Strik (2013) porém, considerado acima do suficiente para Bushway et al. (2008). Esse maior teor de Cu no tecido com aplicação de N pode ser devido ao "efeito priming", no qual a aplicação de $\mathrm{N}$ ativa os microrganismos do solo e aumenta a taxa de mineralização da MO (KUZYAKOV et al., 2000), disponibilizando para as plantas parte do Cu que estava associada a MO do solo (BRUNETTO et al., 2014).
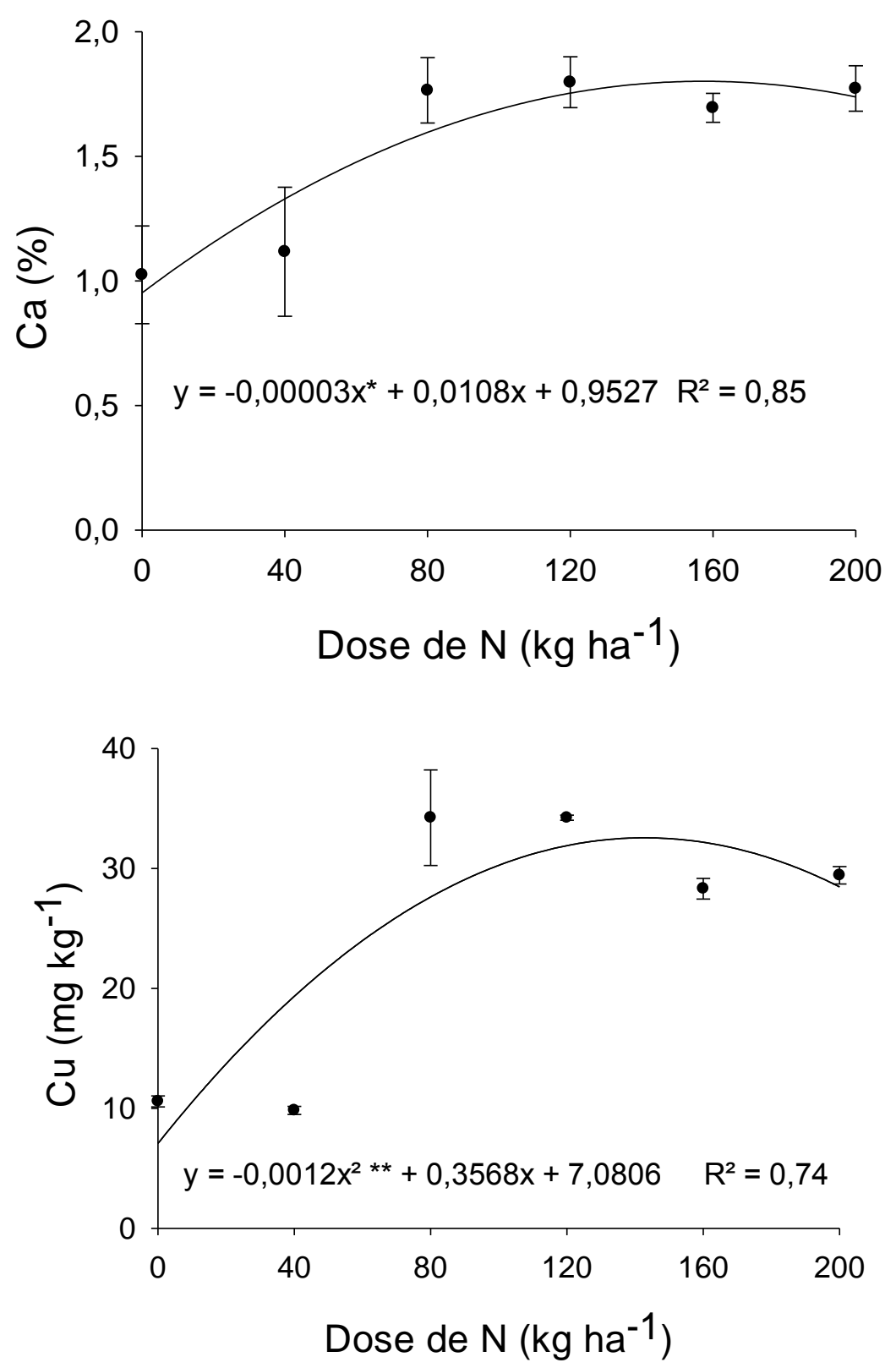

Figura 3. Teores de Ca e Cu no tecido foliar da framboeseira em função da aplicação de $\mathrm{N}$ ao solo. * ${ }^{* *}$ Significativo a $\mathrm{P} \leq 0,05$ e $\mathrm{P} \leq 0,01$ respectivamente. As barras representam o erro padrão para cada tratamento. 
Alguns autores trabalham com os mesmos valores de referência para framboeseira e a amoreira-preta (STRIK, 2013; BUSHWAY et al., 2008) devido à similaridade das espécies, pois pertencem ao mesmo gênero (Rubus) e apresentam porte de planta e estruturas morfológicas semelhantes. Para os estados do Rio Grande do Sul e Santa Catarina há recomendação dos valores de referência para a amoreira preta (COMISSÃO DE QUÍMICA E FERTILIDADE DO SOLO RS/SC, 2016), onde os teores de macro e micronutrientes em tecido foliar encontrados neste estudo foram considerados dentro da faixa normal, a exceção de $\mathrm{N}$ e Mn que ficaram acima do normal.

\section{Conclusão}

Aplicação de nitrogênio no desenvolvimento inicial da framboeseira aumenta o IAF da cultura, porém não apresenta efeito no diâmetro e no número de hastes emergidas. O acúmulo de nutrientes no tecido foliar da framboeseira não é afetado pela aplicação de nitrogênio ao solo, exceto para cálcio e cobre.

\section{Referências}

BRUNETTO, G. et al. Frações de cobre e zinco em solos de vinhedos no Meio Oeste de Santa Catarina. Revista Brasileira de Engenharia Agrícola e Ambiental, v.18, n.8, p. 805-810, 2014. Disponível em: <http://doi:10.1590/1807-1929/agriambi.v18n08p805-810>. Acesso em: 10 jan. 2018.

BURNEY, D.L.; MILES, C. Commercial Red Raspberry Production: in the Pacific Northwest. Washington: Oregon State University, 2007. Disponível em: <https://ir.library.oregonstate.edu/downloads/h702q667h>. Acesso em: 12 Jan 2018.

BUSHWAY, L. et al. Raspberry and Blackberry Production Guide for the Northeast, Midwest, and Eastern Canada, NRAES-35. [S.I:s.n.], 2008. Disponível em: < host31.spidergraphics.com/nra/doc/.../NRAES-35_Web.pdf>. Acesso em: 10 Jan 2018.

CAMINITI, A. Frambuesas: variedades, sistemas de conduccíon y princípios de poda. In: SEMINÁRIO BRASILEIRO SOBRE PEQUENAS FRUTAS, 5.,2009, Vacaria, RS. Anais... Bento Gonsalves: Embrapa Uva e Vinho, 2009.

CAMARGO, F.O. et al. Potencial de mineralização do nitrogênio em solos do Rio Grande do Sul. Revista Brasileira de Ciência do Solo, v. 21, p. 575-579, 1997. 
COWLING, S. A.; FIELD, C. B. Environmental control of leaf area production: Implications for vegetation and land-surface modeling. Global Biogeochemical Cycles. v. 17, p. 7-14, 2003. Disponível em: <doi:10.1029/2002GB001915>. Acesso em: 10 jan. 2018.

COMISSÃO DE QUÍMICA E FERTILIDADE DO SOLO - RS/SC- CQFSRS/SC. Manual de adubação e de calagem para os estados do Rio Grande do Sul e Santa Catarina. 10.ed. Porto Alegre: Sociedade Brasileira de Ciência do Solo, 2004.

COMISSÃO DE QUÍMICA E FERTILIDADE DO SOLO - RS/SC CQFSRS/SC. Manual de calagem e adubação para os estados do Rio Grande do Sul e Santa Catarina. 11.ed. Frederico Westphalen: Sociedade Brasileira de Ciência do Solo, 2016.

CURI, P. N. et al. Produtividade e qualidade da framboeseira 'Batum' cultivada sob cobertura plástica e dois espaçamentos em região subtropical. Ciência Rural, v. 4, 2015. Disponível em: <http://dx.doi.org/10.1590/0103-8478cr20141636> Acesso em: 8 jan 2018.

DRESLER, S. et al. Estimation of the macro- and micronutrient status of raspberries grown in the Lublin region. Folia Horticulturae. v. 27, n.1, p. 53-62, 2015. Disponível em: <http://doi:10.1515/fhort-2015-0014>. Acesso em: 6 jan 2018.

HART, J. et al. Nutrient management guide: Caneberries. EM 8903-E. Washington: Oregon State Universit, 2006.2 Disponível em: <https://ir.library.oregonstate.edu/downloads/db78tc27r>. Acesso em: 5 jan 2018.

KUZYAKOVA, Y. et al. Review of mechanisms and quantification of priming effects. Soil Biology \& Biochemistry, v. 32, p. 1485-1498, 2000. Disponível em: <https://doi.org/10.1016/S0038-0717(00)00084-5>. Acesso em: 5 jan 2018.

OLIVEIRA, P.B. A Planta de Framboesa: morfologia e fisiologia. Divulgação Agro, n. 556, 2007. Disponível em: <http://www.iniav.pt/gca/index.php?id=1183\#13>. Acesso em: 11 jan 2018.

PEREIRA, I. S. et al. Adubação nitrogenada e características agronômicas em amoreira-preta. Pesquisa Agropecuária Brasileira, v. 48, p. 373-380, 2013. Disponível em: <http://dx.doi.org/10.1590/S0100-204X2013000400004>. Acesso em: 11 jan 2018.

RUIZ, H. A. et al. Contribuição dos mecanismos de fluxo de massa e de difusão para o suprimento de K, Ca e Mg a plantas de arroz. Revista Brasileira de Ciência do Solo, v. 23, p. 1015-1018, 1999. Disponível em: <http://dx.doi.org/10.1590/S0100-06831999000400029>. Acesso em: 20 dez. 2017.

SIKIRIC, B. et al. Macronutrient contents in the leaves and fruits of red raspberry as affected by liming in an extremely acid soil. Plant, Soil and Environment, v. 61, p. 23-28, 2011. Disponível em: <http://doi: 10.17221/756/2014-PSE>. Acesso em: 20 dez. 2017.

SIKIRIC, B. et al. Optimization of macroelement contents in raspberry leaves by liming in an extremely acid soil. Spanish Journal of Agricultural Research, v. 9, p. 329-337, 2011. Disponível em:<http://doi: 10.5424/sjar/20110901-450-10>. Acesso em: 10 dez. 2017.

STRIK, B.C.; BRYLA, D.R. Uptake and partitioning of nutrients in blackberry and raspberry and evaluating plant nutrient status for accurate assessment of fertilizer requirements. 
HortTechnology. v. 25, p. 452-459, 2015. Disponível em: < https://ir.library.oregonstate.edu/downloads/8336h3790>. Acesso em: 20 dez 2017.

STRIK, B.C. Nutrient Management of Berry Crops in Oregon. Washington: Oregon State University, 2013. 